\title{
PELATIHAN PENGGUNAAN MEDIA PEMBELAJARAN MANIPULATIF UNTUK MENANAMKAN KONSEP BANGUN RUANG BAGI GURU DI SDN 67 KOTA BENGKULU
}

\author{
Neza Agusdianita \\ Universitas Bengkulu \\ nezaagusdianita@unib.ac.id \\ Viktoria Karjiyati \\ Universitas Bengkulu \\ viktoriakarjiyati@unib.ac.id
}

\begin{abstract}
Abstrak
Sekolah yang dijadikan mitra kegiatan Pengabdian Pada Masyarakat yang sedang diusulkan ini adalah SDN 67 Kecamatan Surabaya Kota Bengkulu. Tujuan dalam PPM ini adalah sebagai berikut (1) untuk meningkatkan pengetahuan guru mengenai pendekatan pembelajaran Realistic Mathematic Education (RME) yang dapat membantu siswa agar lebih mudah memahami materi pembelajaran matematika, (2) untuk meningkatkan pengetahuan guru tentang berbagai media pembelajaran matematika yang sesuai dengan karakteristik siswa SD khususnya untuk konsep bangun ruang dan (3) untuk meningkatkan keterampilan guru dalam menggunakan media pembelajaran manipulatif khususnya untuk konsep bangun ruang. Metode yang digunakan pada kegiatan PPM ini adalah pelatihan dan pendampingan. Pelatihan dilakukan untuk menambah pengetahuan dan waasan guru dalam menggunakan media pembelajaran manipulatif untuk konsep bangun ruang di SD. Setelah guru sasaran menguasai pengetahuan dan keterampilan tersebut, selanjutnya mereka diminta untuk menerapkan keterampilan yang telah dimiliki pada proses pembelajaran sebenarnya di kelas. Hasil kegiatan pengabdian masyarakat ini adalah tersusunnya perangkat pelatihan penerapan media pembelajaran manipulatif untuk konsep bangun ruang bagi guru SDN 67 Kota Bengkulu. Kegiatan Pelatihan Pembuatan Media Pembelajaran Manipulatif untuk Konsep bangun ruang Guru di SDN 67 Kota Bengkulu ini dilaksanakan pada hari Sabtu 23 Agustus 2018 sampai dengan 28 Agustus 2018. Simpulan dari kegiatan ini adalah kegiatan Pelatihan Penggunaan Media Pembelajaran Manipulatif Untuk Menanamkan Konsep Bangun Ruang bagi Guru Di SDN 67 Kota Bengkulu telah terlaksana dengan baik. Tujuan dari kegiatan ini telah tercapai
\end{abstract}

Kata Kunci : Pembelajaran Matematika, Media Manipulatif, dan Bangun Ruang

\begin{abstract}
The school that is being used as a partner for the Community Service activity that is being proposed is SDN 67 Surabaya District, Bengkulu City. The objectives in this PPM are as follows (1) to increase teacher knowledge about Realistic Mathematical Education (RME) learning approaches that can help students understand mathematics learning materials more easily, (2) to increase teacher knowledge about various mathematics learning media that are in accordance with characteristics of elementary school students, especially for the concept of building space and (3) to improve the skills of teachers in using manipulative learning media, especially for the concept of building space. The method used in this activity is training and mentoring. The training was carried out to increase the knowledge and insight of teachers in using manipulative learning media for the concept of building space in elementary schools. After the target teachers have mastered the knowledge and skills, they are then asked to apply the skills they already have in the actual learning process in the classroom. The result of this community service activity is the preparation of training tools for the application of manipulative learning media for the concept of building space for teachers at SDN 67 Bengkulu City. The Training Activity for Making Manipulative Learning Media for the Concept of Teacher's Space Building at SDN 67 Bengkulu City was held on
\end{abstract}


Neza Agusdianita, Viktoria Karjiyati

PELATIHAN PENGGUNAAN MEDIA PEMBELAJARAN MANIPULATIF UNTUK MENANAMKAN

KONSEP BANGUN RUANG BAGI GURU DI SDN 67 KOTA BENGKULU

Saturday, August 23, 2018 until August 28, 2018. 67 Bengkulu City has been implemented well. The purpose of this activity has been achieved.

Keywords : Learning Mathematics, Manipulative Media, and Geometry

\section{Pendahuluan}

Sekolah yang dijadikan mitra kegiatan Pengabdian Pada Masyarakat yang sedang diusulkan ini adalah SDN 67 Kecamatan Surabaya Kota Bengkulu. Sekolah ini terletak di pinggir Kota Bengkulu yang berbatasan dengan Kabupaten Bengkulu Tengah. Prestasi sekolah ini berada pada kategori cukup, artinya prestasi yang diraih oleh sekolah ini masih belum banyak. Jarak sekolah ini sekitar enam kilometer $(\mathrm{km})$ dari kampus PGSD FKIP Unib. SDN 67 Kota Bengkulu ini merupakan sekolah yang jarang dijadikan mitra PPL. SD ini pernah juga menjadi mitra kegiatan pengabdian yang berjudul Penyusunan Perangkat Model Quantum Teaching Dalam Pembelajaran Matematika Menggunakan Rme Untuk Meningkatkan Prestasi Belajar, Kreativitas, Dan Karakter Siswa SD(Agusdianita Neza dan Salati Asmahasanah, 2020). Selain itu juga pernah kegiatan pengabdian dengan judul Pelatihan Dan Pendampingan Penerapan Model Project Based Learning (Pjbl) Dalam Pembelajaran Tematik Bagi Siswa Kelas V SD Negeri 67 Kota Bengkulu (Agusdianita, Neza. Karjiyati Karjiyati, Nani Nuliantini, 2020).Selanjutnya kegiatan yang berjudul Pelatihan Penerapan Model Realistic Mathematics Education Berbasis Etnomatematika Tabut Terhadap Kemampuan Literasi Matematika Siswa Kelas IV SDN 67 Kota Bengkulu (Agusdianita, Neza. Viktoria karjiyati dan Sri ken kustianti, 2021)

Permasalahan yang dihadapi oleh guru di sekolah tersebut dalam pembelajaran matematika adalah bagaimana melaksanakan pembelajaran yang menarik, bermakna dan sesuai dengan perkembangan dan karakteristik siswa SD. Terlebih lagi materi pembelajaran matematika yang bersifat abstrak membuat guru kesulitan dalam menjelaskan materi tersebut. Selain itu ditambah lagi tidak adanya media pembelajaran di sekolah menjadikan siswa semakin sulit untuk memahami materi pembelajaran. Materi yang masih sering dikeluhkan guru ialah konsep bangun ruang. Guru masih perlu mendapatkan pelatihan bagaimana memilih dan membuat media pembelajaran untuk konsep bangun ruang, khususnya untuk perhitungan volume bangun ruang.

Guru SD sangat memerlukan media pembelajaran dalam menjelaskan materi matematika. Hal tersebut dikarenakan tingkat perkembangan anak usia SD berada pada tingkat operasional konkret,artinya siswa mudah memahami suatu konsep jika mereka terlibat langsung memanipulasi benda-benda konkret. Pengalaman fisik dalam memanipulasi benda-benda konkret memiliki peranan penting bagi tahap perkembangan siswa. Karena itu, guru dituntut mampu menciptakan 
Neza Agusdianita, Viktoria Karjiyati

PELATIHAN PENGGUNAAN MEDIA PEMBELAJARAN MANIPULATIF UNTUK MENANAMKAN

KONSEP BANGUN RUANG BAGI GURU DI SDN 67 KOTA BENGKULU

suasana pembelajaran yang kreatif, efektif dan menyenangkan serta melatih siswa berpikir secara sistematis dan berpikir matematis.

Berdasarkan masalah yang dipaparkan di atas, dirasa sangat perlu dilakukan pelatihan pembuatan media pembelajaran matematika untuk konsep bangun ruang. Pelatihan ini dirasakan sangat penting dan berharga bagi guru untuk memperbaiki kualitas proses dan hasil pembelajarannya. Untuk itu diharapkan pelatihan ini dapat dilaksanakan sesegera mungkin demi tercapainya pembelajaran matematika yang inovatif, kreatif dan menyenangkan.

\section{Metode}

Metode yang digunakan pada kegiatan PPM ini adalah pelatihan dan pendampingan. Pelatihan dilakukan untuk menambah pengetahuan dan waasan guru dalam menggunakan media pembelajaran manipulatif untuk konsep bangun ruang di SD. Setelah guru sasaran menguasai pengetahuan dan keterampilan tersebut, selanjutnya mereka diminta untuk menerapkan keterampilan yang telah dimiliki pada proses pembelajaran sebenarnya di kelas. Guru sasaran akan diminta untuk melaksanakan pembelajaran dengan menggunakan media pembelajaran manipulatif yang telah dibuat ketika pelatihan. Tim Dosen akan melakukan pendamping secara terus menerus untuk mengarahkan, membimbing, dan membantu guru sasaran ketika menyusun perangkat pembelajaran dan mengujicobakan perangkat di kelas

\section{Hasil dan Pembahasan}

\section{HASIL}

\section{a. PELAKSANAAN PELATIHAN}

Hasil kegiatan pengabdian masyarakat ini adalah tersusunnya perangkat pelatihan penerapan media pembelajaran manipulatif untuk konsep bangun ruang bagi guru SDN 67 Kota Bengkulu. Perangkat pelatihan ini meliputi Power Point (PPT), lembar wawancara, lembar observasi proses pelatihan, lembar observasi praktik pelaksanaan pembelajaran (RPP).

Kegiatan Pelatihan Pembuatan Media Pembelajaran Manipulatif untuk Konsep bangun ruang Guru di SDN 67 Kota Bengkulu ini dilaksanakan pada hari Sabtu 23 Agustus 2018 sampai dengan 28 Agustus 2018. Peserta pelatihan ini berjumlah 40 orang. Peserta tersebut terdiri dari kepala sekolah dan guru-guru SDN 67 Kota Bengkulu serta mahasiswa. Tahapan kegiatan penelitian ini diantaranya:

1. Penyampaian materi dari tim pengabdi mencakup: Hakikat pembelajaran matematika, materi dan konsep bangun ruang, media pembelajaran konsep bangun ruang. 
Neza Agusdianita, Viktoria Karjiyati

PELATIHAN PENGGUNAAN MEDIA PEMBELAJARAN MANIPULATIF UNTUK MENANAMKAN

KONSEP BANGUN RUANG BAGI GURU DI SDN 67 KOTA BENGKULU

2. Diskusi dengan peserta pelatihan tentang materi yang telah disampaikan

3. Mempraktekkan membuat media pembelajaran manipulatif untuk konsep bangun ruang.

4. Mempraktikkan menerapkan media pembelajaran manipulatif yang dibuat pada kelas IV DN 67 Kota Bengkulu pada tanggal 27 Agustus 2018.

Dokumentasi kegiatan pengabdian pada masyarakat ini adalah sebagai berikut:

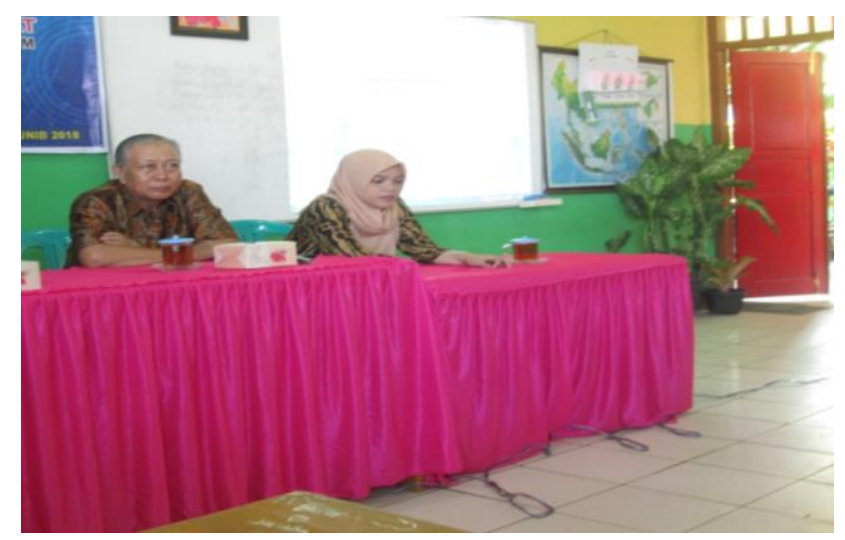

Gambar 1. Acara pembukaan kegiatan pengabdian pada masyarakat

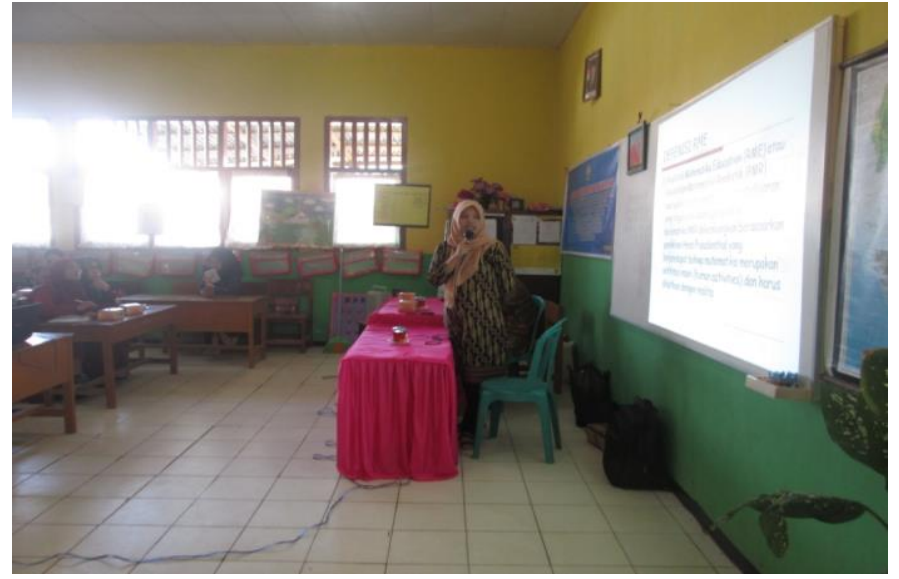

Gambar 2. Penyampaian materi oleh Neza Agusdiantia, M.Pd

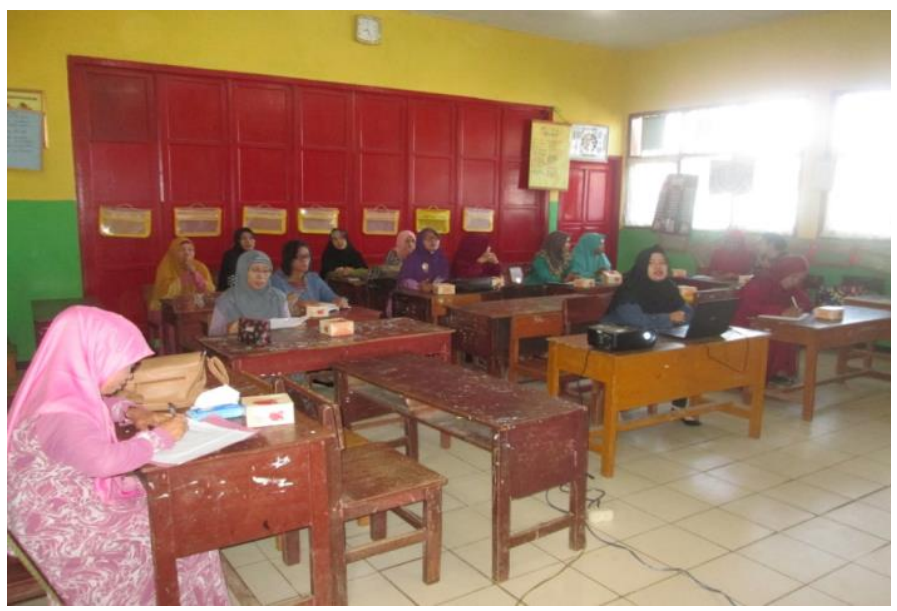




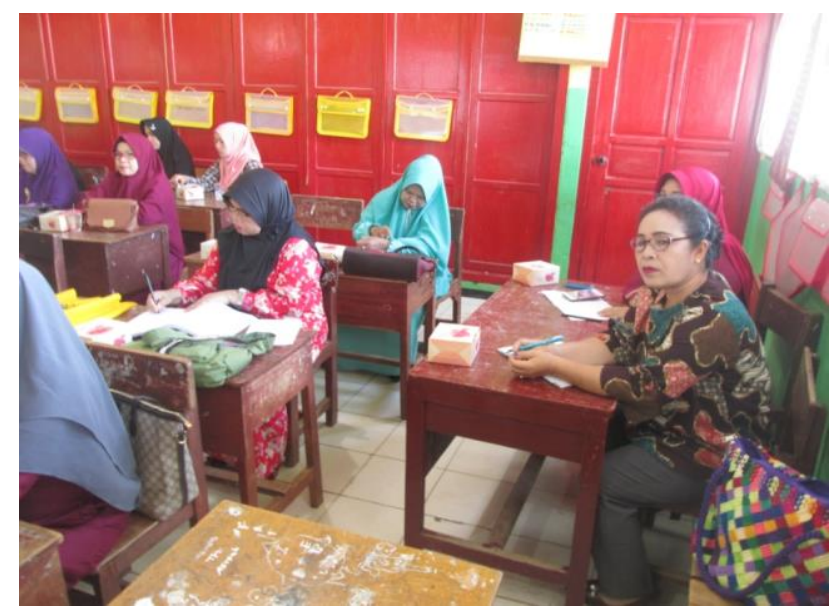

Gambar 3 dan 4 Diskusi peserta kegiatan dan tim dosen pelaksana

\section{b. PELAKSANAAN EVALUASI}

Untuk mengetahui keberhasilan pelaksanaan pelatihan, maka telah dilakukan evaluasi terhadap pemahaman dan keterampilan guru dalam menerapkaan media pembelajaran pada konsep bangun ruang. Evaluasi yang telah dilakukan adalah:

1. wawancara tentang pemahaman awal guru tentang konsep bangun ruang dan medianya. Wawancara ini juga dilakukan untuk mengetahui kesulitan guru dalam pembelajaran bangun ruang.

2. Kemudian observasi pada saat kegiatan pelatihan berlangsung untuk melihat keterampilan guru dalam membuat media. Hasil Observasi menunjukkan semua kegiatan pelatihan diikuti oleh semua peserta pelatihan dengan baik .

3. Terakhir Pengabdi melakukan observasi keterampilan guru dalam mempraktikkan pembelajaran konsep bangun ruang menggunakan media manipulatif pada tanggal 27 Agustus 2018. Hasil dari kegiatan ini ialah guru telah dapat mempraktikkan menerapkan media pembelajaran manipulatif di kelas IV SDN 67 Kota Bengkulu dengan baik.

\section{PEMBAHASAN}

Kegiatan pengabdian kepada masyarakat kali ini berjudul pelatihan penerapan media pembelajaran manipulatif untuk konsep bangun ruang bagi guru SDN 67 Kota Bengkulu. Pelatihan ini bertujuan untuk melatih guru-guru di SDN 67 Kota Bengkulu dalam menerapkan media pembelajaran matematika pada konsep bangun ruang. Dengan memiliki keterampilan menerapkan media pembelajaran maka guru dapat menyelenggarakan pembelajaran yang bermakna. 
Neza Agusdianita, Viktoria Karjiyati

PELATIHAN PENGGUNAAN MEDIA PEMBELAJARAN MANIPULATIF UNTUK MENANAMKAN

KONSEP BANGUN RUANG BAGI GURU DI SDN 67 KOTA BENGKULU

Bangun ruang adalah konsep matematika yang sifatnya konkret yaitu dapat dilihat, diraba dan dimanipulasi oleh siswa. Siswa pun juga sudah memiliki pengalaman mengenai berbagai bangun ruang yang ada di kehidupannya sehari-hari. Dengan demikian dalam mengajarkan konsep ini guru hendaknya menggunakan berbagai media pembelajaran sehingga siswa akan mudah memahami tujuan dari pembelajaran matematika tersebut.

Media-media yang dibuat adalah media yang dapat dimanipulasi oleh siswa sehingga siswa dapat menemukan konsep melalui pengalaman langsung. Bruner (dalam Dahar, 2011) menjelaskan ada tiga cara penyajian informasi, yaitu: (1) tahap enaktif, dalam hal ini siswa secara langsung terlibat dalam memanipulasi objek, (2) tahap ikonik, pada tahap ini siswa dibimbing untuk memahami konsep bangun ruang itu menggunakan gambar di papan tulis, dan (3) tahap simbolik, pada tahap ini siswa memanipulasikan simbol-simbol atau lambang-lambang objek tertentu. siswa benar-benar memahami konsep bangun ruang tanpa menggunakan benda manipulatif dan gambar.

Selain Bruner, Dale juga menunjukkan bahwa pengalaman langsung paling baik dalam membantu anak dalam menyerap informasi. Selain itu juga didukung oleh pendapat Piaget dalam Sumantri (2006) yang menjelaskan bahwa siswa SD berada pada tahap operasional kongkrit, dimana mereka dapat berpikir secara sistematis untuk mencapai pemecahan masalah. Pada tahap ini permasalahan yang dihadapi yaitu permasalahan kongkrit. Hal itu diperkuat oleh teori Magnesen (Depotter, 2008) yang menyatakan bahwa kita belajar 10\% dari yang kita baca, 20\% dari apa yang kita dengar, 30\% dari apa yang kita lihat, 50\% dari apa yang kita lihat dan kita dengar, 70\% dari apa yang kita lakukan, 90\% dari apa yang kita katakan dan lakukan. Dengan demikian pembelajaran matematika dengan menggunakan benda-benda manipulatif diharapkan akan mampu membantu siswa dalam memahami konsep-konsep matematika.

Media pembelajaran manipulatif yang dapat digunakan dalam mengajarkan konsep volume bangun ruang yaitu model berbagai bangun ruang yang terbuat dari kertas mika atau kaca. Model bangun ruang yang dibuat yaitu kubus, balok, prisma, tabung, limas, kerucut, dan bola. Selain itu media manipulatif selanjutnya yaitu kubus satuan, pasir, atau air yang dapat digunakan untuk menurunkanrumus volume bangun ruang. Selain itu berdasarkan penelitian yang dilakukan oleh Agusdianita, Neza. W Widada, N H Afriani, H Herawati, D Herawaty and K U Z Nugroh. (2021) menyatakan bahwa "The geometrical concepts that exist in the Tabot culture were the cube, the beam, the pyramid, the prism, the sphere and its elements. Also, understanding of twodimensional figure". Dengan demikian guru bisa memanfaatkan media etnomatematika Tabut juga sebagai alternatif mengajarkan bangun ruang. Ditambahkan juga melalui mengajarkan matematika dengan etnomatematika dapat meningkatkan kemampuan literasi matematika (Agusdianita, Neza. 
Neza Agusdianita, Viktoria Karjiyati

PELATIHAN PENGGUNAAN MEDIA PEMBELAJARAN MANIPULATIF UNTUK MENANAMKAN

KONSEP BANGUN RUANG BAGI GURU DI SDN 67 KOTA BENGKULU

Victoria Karjiyati, Sufiyandi,2020) dan (Saraseila, Fasadena V Karjiyati, Neza Agusdianita,

2020). Seperti kita ketahui kemampuan literasi sangat dibutuhkan pada zaman sekarang ini.

\section{Kesimpulan}

Simpulan dari kegiatan ini adalah kegiatan Pelatihan Penggunaan Media Pembelajaran Manipulatif Untuk Menanamkan Konsep Bangun Ruang bagi Guru Di SDN 67 Kota Bengkulu telah terlaksana dengan baik. Tujuan dari kegiatan ini telah tercapai.

\section{Penghargaan/Ucapan terima kasih}

Terimakasih kepada pihak FKIP dan LPPM Universitas Bengkulu yang telah memberikan pendanaan kegiatan melalui hibah pengabdian pada masyarakat program S1 PGSD.

\section{Daftar Pustaka}

Adjie \& Rostika. (2006). Konsep Dasar Matematika. Bandung: UPI Press

Agusdianita Neza, Salati Asmahasanah. (2020). Penyusunan Perangkat Model Quantum Teaching Dalam Pembelajaran Matematika Menggunakan Rme Untuk Meningkatkan Prestasi Belajar, Kreativitas, Dan Karakter Siswa SD. Attadib Journal Of Elementary Education, Vol. 4 (1), Juni 2020

Agusdianita,Neza.(2013). Pengaruh Model Pembelajaran Quantum Teaching Terhadap Kemampuan Pemahaman Matematik Siswa Sekolah Dasar. Laporan Tesis. Bandung: UPI

Agusdianita, Neza. Karjiyati Karjiyati, Nani Nuliantini. 2020. Pelatihan Dan Pendampingan Penerapan Model Project Based Learning (Pjbl) Dalam Pembelajaran Tematik Bagi Siswa Kelas V SD Negeri 67 Kota Bengkulu. Martabe Jurnal Pengabdian Pada Masyarakat. Vol 3, No 1.

Agusdianita, Neza. Victoria Karjiyati, Sufiyandi.(2020). The Use of Ethnomathematics Learning Devices Based on Realistic Mathematics Education Models on Mathematics Literacy Mastery. Series Advances in Social Science, Education and Humanities Research. Atlantis Press. Proceedings of the International Conference on Educational Sciences and Teacher Profession (ICETeP 2020). https://doi.org/10.2991/assehr.k.210227.054

Agusdianita, Neza. Viktoria karjiyati dan Sri ken kustianti. 2021. Pelatihan Penerapan Model Realistic Mathematics Education Berbasis Etnomatematika Tabut Terhadap Kemampuan Literasi Matematika Siswa Kelas IV SDN 67 Kota Bengkulu. Martabe Jurnal Pengabdian Pada Masyarakat. Vol 4, No 1 (2021) 
Neza Agusdianita, Viktoria Karjiyati

PELATIHAN PENGGUNAAN MEDIA PEMBELAJARAN MANIPULATIF UNTUK MENANAMKAN

KONSEP BANGUN RUANG BAGI GURU DI SDN 67 KOTA BENGKULU

Agusdianita,Neza. W Widada, N H Afriani, H Herawati, D Herawaty and K U Z Nugroh. (2021). The exploration of the elementary geometry concepts based on Tabot culture in Bengkulu. Journal of Physics: Conference Series. $1731 \quad$ (2021) 012054IOP Publishingdoi:10.1088/1742-6596/1731/1/012054. OP Publishing

Kelly, C A. (2006). Using Manipulative in Mathematival Problem Solving: A Performance Based Analysis.

Maizon, Hepi. (2010). Pembelajaran Kuantum untuk Meningkatkan Kemampuan Pemahaman Matematika dan Motivasi Belajar Siswa. Tesis Program Studi Pendidikan Matematika Pascasarjana Universitas Pendidikan Indonesia. Bandung: Tidak diterbitkan

Saraseila, Fasadena V Karjiyati, Neza Agusdianita. (2020). Pengaruh model realistic mathematics education terhadap kemampuan literasi matematika siswa kelas $V$ sekolah dasar gugus XIV kota bengkulu. Jurnal math-umb.edu. Vol 7 No 2

Sari, Atikah. (2009). Pemberdayaan Benda Manipulatif dalam Pembelajaran Matematika untuk Meningkatkan Kemampuan Pemahaman dan Penalaran Siswa Sekolah Dasar. Tesis Program Studi Pendidikan Dasar Pascasarjana Universitas Pendidikan Indonesia.Bandung: Tidak diterbitkan

Wahyudin. (2012). Filsafat dan Model-Model pembelajaran Matematika (Pelengkap untuk Meningkatkan Kompetensi Pedagogis Para Guru dan Calom Guru Profesional. Bandung : Mandiri 